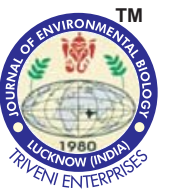

\title{
CLIMEX modelling for risk assessment of Asian fruit fly, Bactrocera papayae (Drew and Hancock, 1994) in India
}

Authors Info

V. Sridhar" ${ }^{1 *}$ L.S. Vinesh ${ }^{1}$, M. Jayashankar', P.D. Kamala Jayanthi' and Abraham Verghese ${ }^{2}$

'Division of Entomology and Nematology, Indian Institute of Horticultural Research, Bengaluru-560 089, India

${ }^{2}$ National Bureau of Agricultural Insect Resources, Bengaluru-560 024, India

${ }^{*}$ Corresponding Author Email : vsridhar@iihr.res.in

Key words

Bactrocera papayae,

Climate change,

CLIMEX, modelling,

Quarantine pest

Publication Info

Paper received : 13.07 .2015

Revised received:08.02.2016

Re-revised received : 06.06.2016

Accepted : 08.06.2016
Abstract

Aim : Risk of establishment of Asian fruit fly, Bactrocera papayae (Drew and Hancock, 1994) an alien species to India was made for the present and expected climate change situations of $1^{\circ} \mathrm{C}, 2^{\circ} \mathrm{C}$ and $3^{\circ} \mathrm{C}$ rise in global temperatures using CLIMEX, a bioclimatic modelling tool.

Methodology : CLIMEX, the bioclimatic model was run for 33 known geo-referenced home locations of $B$. papayae using "regional match climate" function in order to predict the areas with similar Climate Match Index, $(\mathrm{CMI}>0.7)$. The model was also run with rise in temperature of $1^{\circ} \mathrm{C}, 2^{\circ} \mathrm{C}$ and $3^{\circ} \mathrm{C}$ for predicting the risk areas for $B$. papayae establishment, in case gets introduced accidentally.

Results : High climatic similarity was predicted for most parts of South East Asia, Africa, South America, few parts of Australia, North Western Europe, North and Central America. In India, a climate match of $>0.7$ was predicted for the states of Karnataka, Tamil Nadu, Andhra Pradesh, Telangana, Orissa, Bihar, Jharkhand, West Bengal, Maharashtra, Kerala and Chhattisgarh, which could be potential hot spots for B. papayae, if introduced accidentally. In India, with the rise in temperatures from $1^{\circ} \mathrm{C}$ to $3^{\circ} \mathrm{C}$, there was a gradual decrease in the climate similarity for the pest establishment, particularly in the coastal regions of Tamil Nadu and Andhra Pradesh. However, the climate similarity was projected to increase in the coastal parts in the states of Karnataka and Maharashtra with $3{ }^{\circ} \mathrm{C}$ rise in temperature, making the regions more suitable for pest establishment.

Interpretation : Present findings emphasises the need for close monitoring in the regions predicted to have congenial climatic conditions for $B$. papayae and needs strict quarantine measures against this pest. 


\section{Introduction}

Insects are ubiquitous inhabiting extreme terrains like swamps, forests, deserts, temperate regions and as pests causes major damage to various crops resulting in high economic loss in the agricultural sector worldwide (Mohamed, 1999). In spite of numerous advances in plant protection, native and invasive insects continue to pose serious threat to agriculture. In such a challenging condition, invasions by non-indigenous species are a problem of increasing magnitude that threatens the stability of the world's agricultural ecosystems (Liebhold et al., 2006). To check the entry, establishment and spread of the invasive species, usually risk maps for Pest Risk Analysis (PRA) are being generated (Robinet et al., 2012). One such effective climate matching function of CLIMEX was used in the present study to evaluate the climatic similarity between the existing areas of the Asian fruit fly, Bactrocera papayae (Drew and Hancock, 1994) (Diptera: Tephritidae) and other locations in the world. Biological control agents from areas with similar climatic conditions are considered to be more likely to achieve effective control (Hoelmer and Kirk, 2005). Thus, climate matching can also be used to identify climatically suitable regions for selection of bioagents (Byrne et al., 2002; Senaratne et al., 2006 and Robertson et al., 2008).

B. papayae, a member of Oriental fruit fly complex is widespread in South-East Asia with high economic impacts (Allwood et al., 1999; Hancock et al., 2000; Cantrell et al., 2002) is a polyphagous pest having more than 193 hosts belonging to 114 genera and 50 families (Allwood et al., 1999) and mainly spreads through fruits containing larvae either as part of cargo or accidentally carried by passengers. It infests a wide range of horticultural crops including banana, star fruit, guava, mango, papaya, almond etc. (Wee and Tan 2000; Clarke et al., 2005). Infestation by fruit flies lead to loss of up to $12-60 \%$ in mango and papaya and $40-90 \%$ in guava (Allwood and Leblanc, 1997). In Thailand, the pest usually occurs during August-September and in May (Danjuma et al., 2014). Its high dispersive ability, large host range and occurrence in both forest and non-forest habitats makes it a potential threat to horticultural crops (CABI, 2015). Its recent invasion to Australasian region is alarming though the pest is said to have been successfully eradicated at a cost of about AU\$35 million (Fay et al., 1997; Hancock et al., 2000; Sar et al., 2001; Cantrell et al., 2002).

The range of temperature elevation is expected to be 1.1 to $6.4^{\circ} \mathrm{C}$ by the end of this century (IPCC climate change, 2007). This expected climate change might affect the distribution of insects either directly by changing survival and fecundity rate or indirectly influencing availability of food source, natural enemies and competitors (Baker and Bomford, 2009). Climate change also predicted range expansions or migrations from unsuitable regions to suitable regions particularly poleward expansion of the species that are currently limited by prevailing low temperatures
(Daniel, 2015).

CLIMEX software is widely used in predicting and mapping the potential geographic distribution of climate dependent trans-boundary pests and diseases (Sutherst and Floyd, 1999; Sutherst, 2003). Such bioclimatic models are used to predict geographic ranges of organisms as a function of climate to forecast range shifts due to climate change, to predict the eventual ranges of invasive species and infers paleoclimate from data on species occurrences (Ganeshaiah et al., 2003; Sutherst and Maywald, 2005; Jeschke and Strayer, 2008). Apart from CLIMEX, prediction models like BioClim, GARP and MaxEnt are also widely used to predict the potential geographical distribution of flora and fauna (Rameshprabhu and Swamy, 2015; Rajasri et al., 2011; Kumar et al., 2014). The aim of the present study was to predict climate suitability for Asian fruit fly, B. papayae infestation at global level with special reference to India through CLIMEX modelling based on the present distribution of the pest. The predictions were made for both present and future climate conditions with a rise of $+1,+2$ and $+3^{\circ} \mathrm{C}$ in temperature.

\section{Materials and Methods}

Known distribution of $B$. papayae: Asian fruit fly, $B$. papayae is wide spread in South EastAsia (Fig. 1). It has been recorded from Oceania: Australia (Queensland - Torres Straits islands and Cairns areas), Papua New Guinea (Sutherst and Floyd, 1999) and is reported to have been eradicated from Queensland (CABI, 2015).

CLIMEX: Match climate function of CLIMEX ver 3.0 was used to compare the climate of home locations (known distribution) with away locations (area under investigation) to infer the preferred climate by the target pest. Climate matching consisted of selecting a location and then looking for locations elsewhere that have a similar climate enabling us to compare the meteorological data from different places and the extent of similarity. A Match Climates analysis showed whether the climate of 'away' location was similar to the 'home' locations, which would impact the preference of the locations for the establishment of the pest. In the present study, 33 home locations of known records (Fig.1) of $B$. papayae in the world were selected using the 'MetManager Location Selection' and the model was run with match climate regional application considering other locations in the world as 'away'. The resulting Composite Match Index, CMI (0-1) (Sutherst and Maywald, 2005) i.e., the similarity between 'home' and 'away' locations provides a probable risk of a pest establishing in a new location (country, continent) with implications for quarantine and pest risk analysis. CMI is the product of six indices viz., Itmax, Itmin, Irain, Irpat, Ihum and Ism, indicating similarity in maximum/minimum temperature, total rainfall, rainfall pattern, relative humidity and soil moisture, respectively. $\mathrm{ACMI}$ value of 0.7 is generally accepted as the threshold for a biologically relevant climate match (Robertson et al., 2008; Kriticos 2012). In 
addition, a climate change scenario of elevated temperature of $+1,+2$ and $+3^{\circ} \mathrm{C}$ for all the locations was included for running the model to arrive at Composite Match Index and to know about suitable locations in future when compared to the present spread of the pest. For climate data, CliMond 30 gridded data (Kriticos et al., 2012) comprising of more than 68,000 locations was used for the present modelling.

\section{Results and Discussion}

The climate match map generated for the global scenario for the base year (averaged at 1975) is presented in Fig. 2 and confirms to the present distribution range of $B$. papayae in South EastAsia (Fig. 1). High similarity in climate was seen in most parts of southern, central and eastern India, most parts of Bangladesh, Burma, Thailand, Cambodia, Vietnam, Taiwan, Japan, Malaysia, Singapore, Indonesia, Philippines and southern parts of Sri Lanka (Fig. 2). In Australia (northern parts of northern territory, northern Queensland, parts of southern Victoria) and North America parts of eastern US, southern part of Mexico, Guatemala, El Salvador, Belize, Honduras, Nicaragua, Panama, Bahamas, Turks and Caicos are expected to be similar. Most parts of South America (Brazil, Peru, Bolivia, Ecuador, Colombia, Venezuela, Guyana, and French Guiana) and Europe (Northern Portugal, Spain, most parts of France, Switzerland, Italy, England, Wales, Ireland, Scotland, Belgium, Netherland, Denmark, parts of Germany, Austria) have similar climatic conditions, and hence with the availability of the host, the pest was expected to establish successfully in these regions. With most parts showing a $\mathrm{CMI}$ value of $0.6-0.7$, China region could be less suitable for the establishment of $B$. papayae.

In India, north eastern parts of Andhra Pradesh, most parts of Telangana, southern tip of Chattisgarh, Orissa and southern Andaman had a climate match index of 0.8-0.9. High climate match $(70-80 \%)$ was predicted in most parts of Orissa, central Chattisgarh, most regions of West Bengal, entire Assam, northern Arunachal Pradesh, entire Manipur, Nagaland and parts of Tripura and Mizoram with parts of Uttarakhand, Himachal Pradesh, Jammu, Andaman and Nicobar and Lakshadweep (Fig. 3). The aforesaid regions harbour numerous horticultural crops, most of which are known to be hosts of $B$. papayae in its native range (CABI, 2015). Below 0.6\% CMI was observed in Kashmir, Meghalaya, Sikkim, most parts of Rajasthan, northern regions of Gujarat, few parts of Mizoram and Tripura, which might not favour the establishment of the pest. Poutsma et al. (2008) used CLIMEX as a strategic tool for estimating establishment potential as part of an environmental risk assessment for biological control agents like harlequin ladybird, Harmonia axyridis.

In future, climate change mediated elevated temperatures of $+1,+2$ and $+3^{\circ} \mathrm{C}$ in Asia would result in gradual reduction of overall climatic similarity for the successful establishment of the pest (Fig. 4a-c). The per cent change in area similar to the home locations is projected to decrease from $4.76 \%$ for the base year to $4.4 \%$ at $3^{\circ} \mathrm{C}$ increase in global temperature (Fig. 5). In most regions of Myanmar, Vietnam, Laos, Cambodia, Singapore, Indonesia and parts of Malaysia, the climatic similarity was expected to decrease. Similar modelling studies using CLIMEX under climate change context, future predictions on distribution of tomato leaf miner, Tuta absoluta indicated that the invasive nature of this pest will result in significant crop loss in certain locations, whereas some parts of Africa may witness diminution in ranges (Tonnang et al., 2015).

In Australia, similarity in climate was expected to decrease from $11.78 \%$ in the base year to $9.32 \%$ at $+3^{\circ} \mathrm{C}$ increase in temperature (Fig. 5). Similarity was projected to be very less in northern territory (Kakadu and Katherine) and northern regions of Queensland and Western Australia. Similarity was also expected to decrease in Victoria and Tasmania (Fig. 4a-c). In Europe, significant decrease in climate match was predicted in France, Spain, Portugal and Turkey with an overall decrease in suitability from $22.76 \%$ in the base year to $18.29 \%$ at $+3^{\circ} \mathrm{C}$ rise in temperature (Fig. 5). On the other hand, presently cold regions of Norway and Sweden were expected to have slightly similar climatic conditions under climate change even at $3^{\circ} \mathrm{C}$ rise in temperature (Fig. 4a-c).

In South America, the climate similarity for invasive pest was expected to increase from $53.06 \%$ in the base year to $55.59 \%$ in future scenario of $+3^{\circ} \mathrm{C}$ increase in temperature (Fig. 5). A decreasing similarity in climate was observed in Brazil, Peru, Venezuela, Guyana and Bolivia by $3^{\circ} \mathrm{C}$ increase in temperature. In case of southern coastal regions of Chile and Falkland Island, climatic similarity is expected to increase with increase in temperature (Fig. 4a-c). In North America, the climate similarity for the pest was expected to decrease from $8.05 \%$ in the base year to $7.56 \%$ in future scenario of $+3^{\circ} \mathrm{C}$ increase in temperature (Fig. 5) with more or less similar climatic conditions (Fig. 4a-c).

In Africa, under projected elevated temperatures of +1 , +2 and $+3^{\circ} \mathrm{C}$, the overall similarity in climate for successful establishment of the pest was expected to gradually increase from $25 \%$ in the base year to $28.61 \%$ at $3^{\circ} \mathrm{C}$ increase in temperature (Fig. 5). Increase in climatic similarity was seen in Cameroon, Central African Republic, Ethiopia, south Sudan and Zimbabwe. A decrease in similarity was observed in central and eastern Africa, Congo, Gabon and parts of South Africa (Fig. 4a-c).

In Africa and South America, climate similarity in many locations was expected to gradually increase with increase in temperature (Fig. 4c). On the other hand, in Asia, Australia, North America and Europe, regions with dissimilar climate for the establishment of pest were projected to increase leading to lesser regions of climatic similarities. 
In India, with the rise in temperatures from $1^{\circ} \mathrm{C}$ to $3^{\circ} \mathrm{C}$, there was a gradual decrease in the climate similarity for the pest establishment, particularly in the coastal regions of Tamil Nadu and Andhra Pradesh. However, similarity was projected to increase in the coastal parts of Karnataka and Maharashtra and in parts of Odisha at $3^{\circ} \mathrm{C}$ increase in temperature. Under Indian conditions, possible change in the potential distribution of Oriental fruit fly, B. dorsalis (Sridhar et al., 2014a) and giant African snail, Achatina fulica (Sridhar et al., 2014b) in future as a consequence of predicted climate change was established through CLIMEX modelling.

Climatic envelope for $B$. papayae revealed $B$. papayae preferred an annual mean temperature range of $17-28^{\circ} \mathrm{C}$, with around 22 locations (out of 33 ) lying between $24-28{ }^{\circ} \mathrm{C}$. The maximum, minimum temperature range and annual precipitation ranged from $24-33^{\circ} \mathrm{C}, 11-23^{\circ} \mathrm{C}$ and $1200-3600 \mathrm{~mm}$, respectively (Fig. 6a-c)

Bioclimatic models assess the bio-physiological aspects of a species to generate the condition in which the species can ideally exist. In India, potential geographical distribution maps of many agriculture pests are generated using different modeling softwares like GARP, DIVA-GIS and MAXent for present and future climate change situations (Ganeshaiah et al., 2003; Babasaheb, 2012). Although the above mentioned models are being successfully employed for predicting the spread of pest species, for the first time in the present study CLIMEX was explored as a modelling approach to predict the potential geographical distribution of invasive pest, B. papayae in India and elsewhere. Climate match helps us to know the exact climatic preference of the pest which can be used in identifying the regions that are suitable for the pest. The present study was undertaken as there is a need to assess the extent of establishment risk by this quarantine pest in vulnerable regions. Most regions with similarity range of $0.7-0.9 \mathrm{CMl}$ were hot spots for agrihorticultural crops like almond, mango, guava, coffee, tomato, papaya etc. which were considered to be the major hosts of $B$. papayae. In future, invasion of $B$. papayae would worsen the pest status in these horticultural crops in future as many fruit fly species could compete for the same ecological niche due to their similar feeding habits.

Similarity in climate was seen in most parts of southern, central and eastern India, most parts of Bangladesh, Burma, Thailand, Cambodia, Vietnam, Taiwan, Japan, Malaysia, Singapore, Indonesia, Philippines and southern parts of Sri Lanka. In South America, most parts of Brazil, Peru, Bolivia, Ecuador, Colombia, Venezuela, Guyana, and French Guiana are expected to have similar climatic conditions as compared to the home locations. In Australia, northern parts of northern territory (Australia), northern Queensland, parts of southern Victoria were expected to be climatically similar. In North America most parts of eastern US was expected to have highly similar climatic
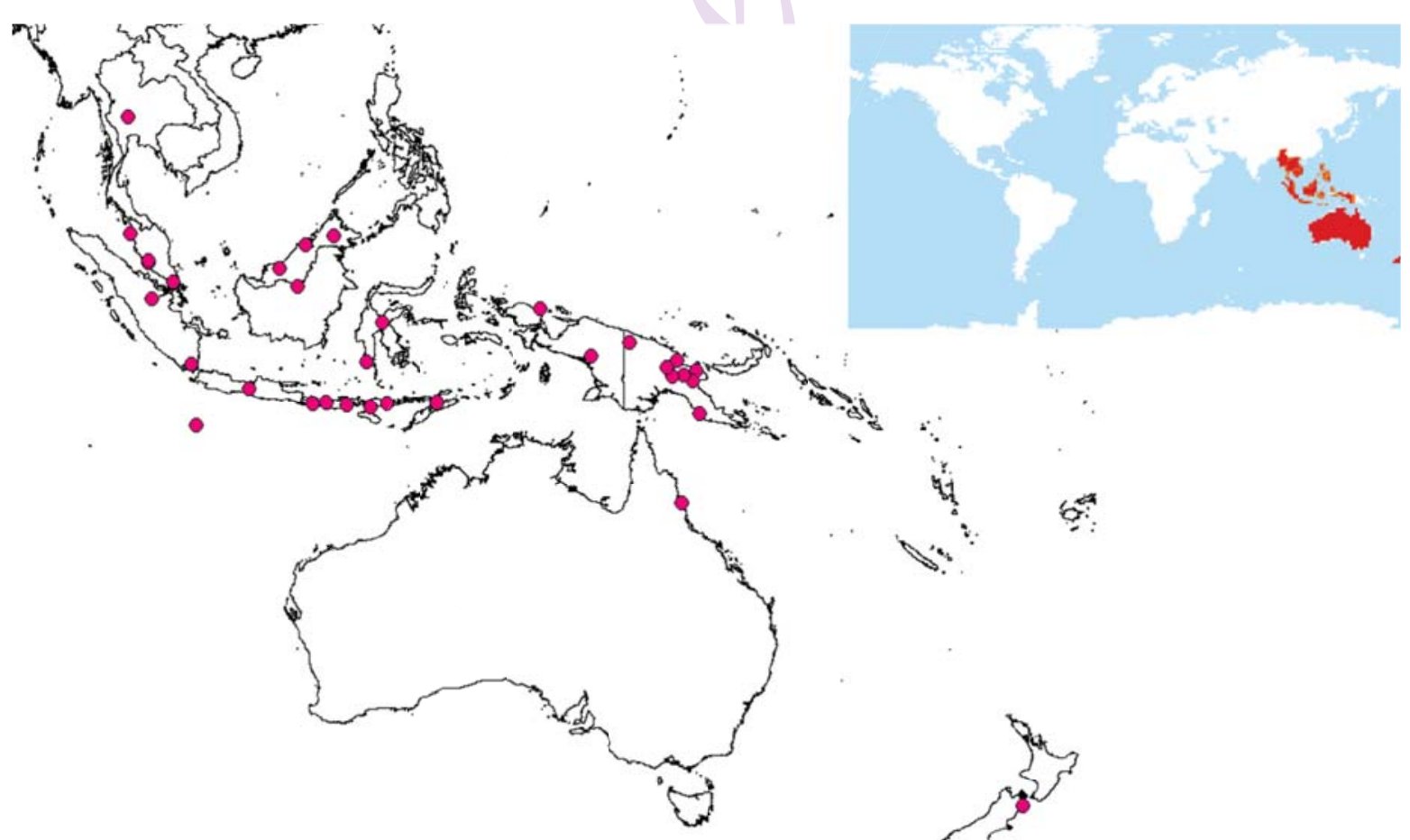

Fig. 1 : Current global distribution of $B$. papayae (CABI, 2015)

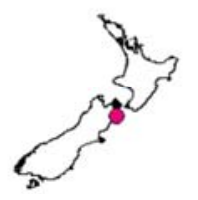

Journal of Environmental Biology, January 2017 


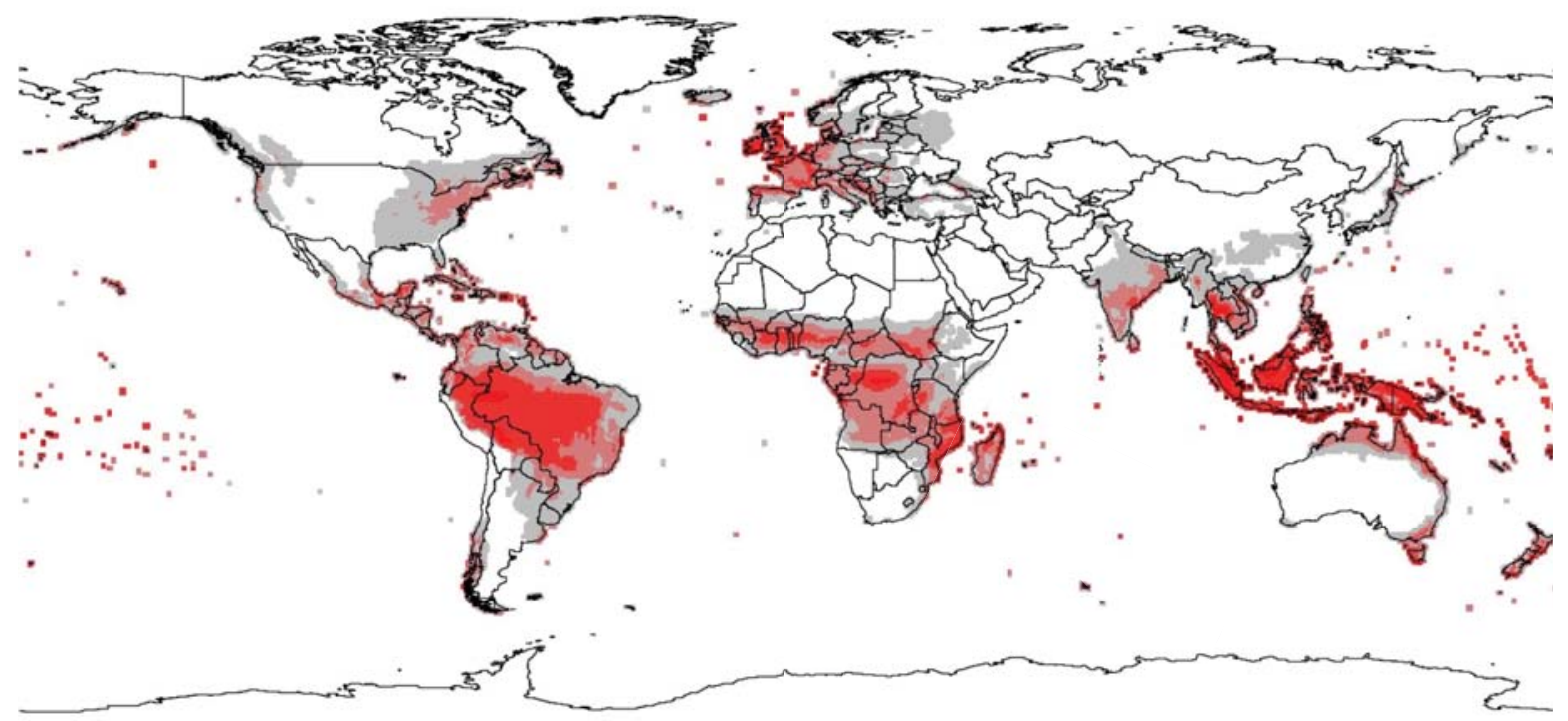

CMI values: $\square 0-0.6$ (0-60\% matching); $\square 0.6-0.7$ (60-70\% matching); $\square 0.7-0.8$ (70-80\% matching); $\square 0.8-0.9$ (80-90\% matching); $\square 0.9-1.0$ (90$100 \%$ matching)

Fig. 2 : Global potential areas for B. papayae in terms of climate match (1961-1990)
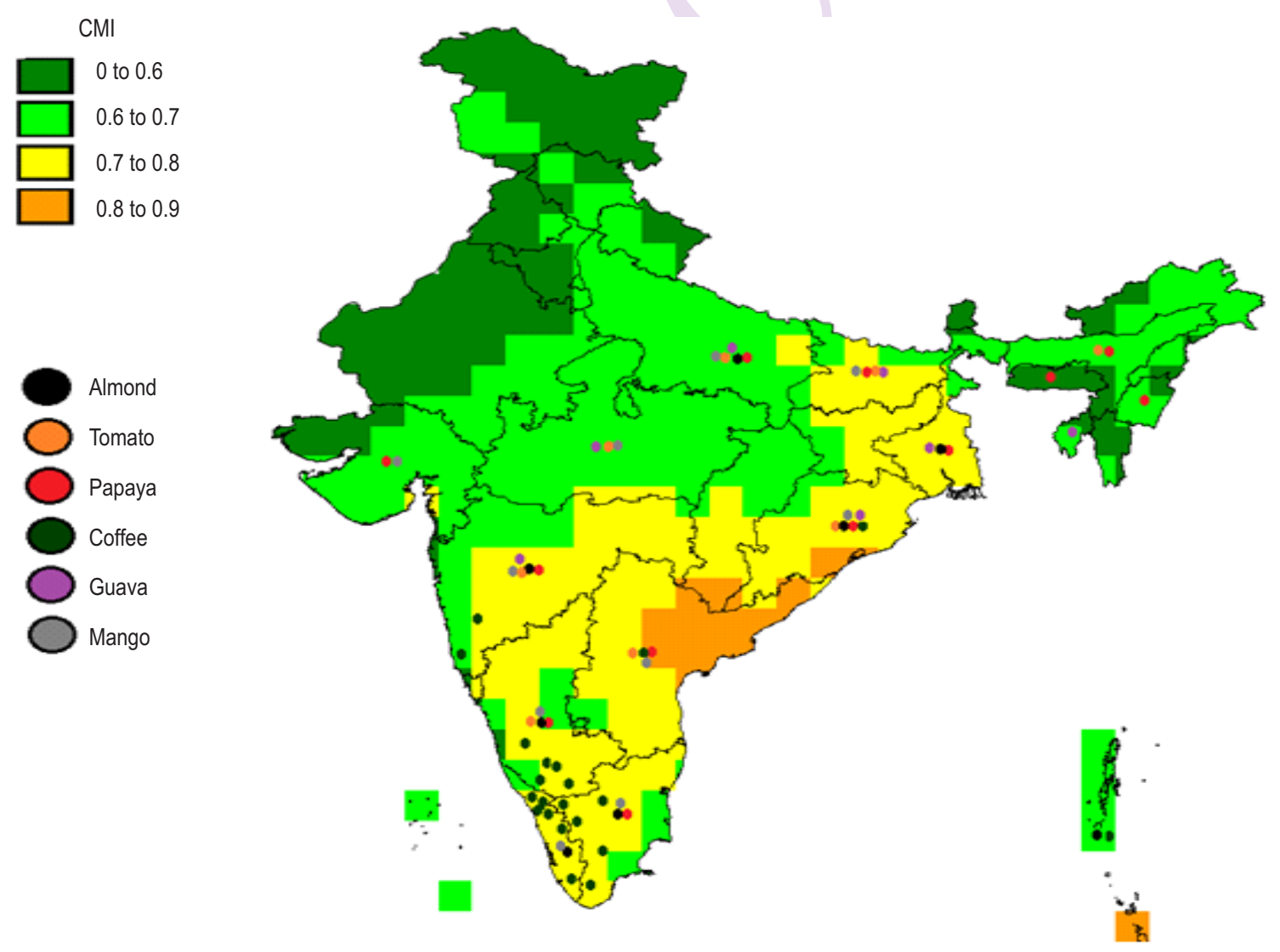

Fig. 3 : Potential areas for B. papayae establishment in India with major host distribution (CMI=Composite Match Index) 

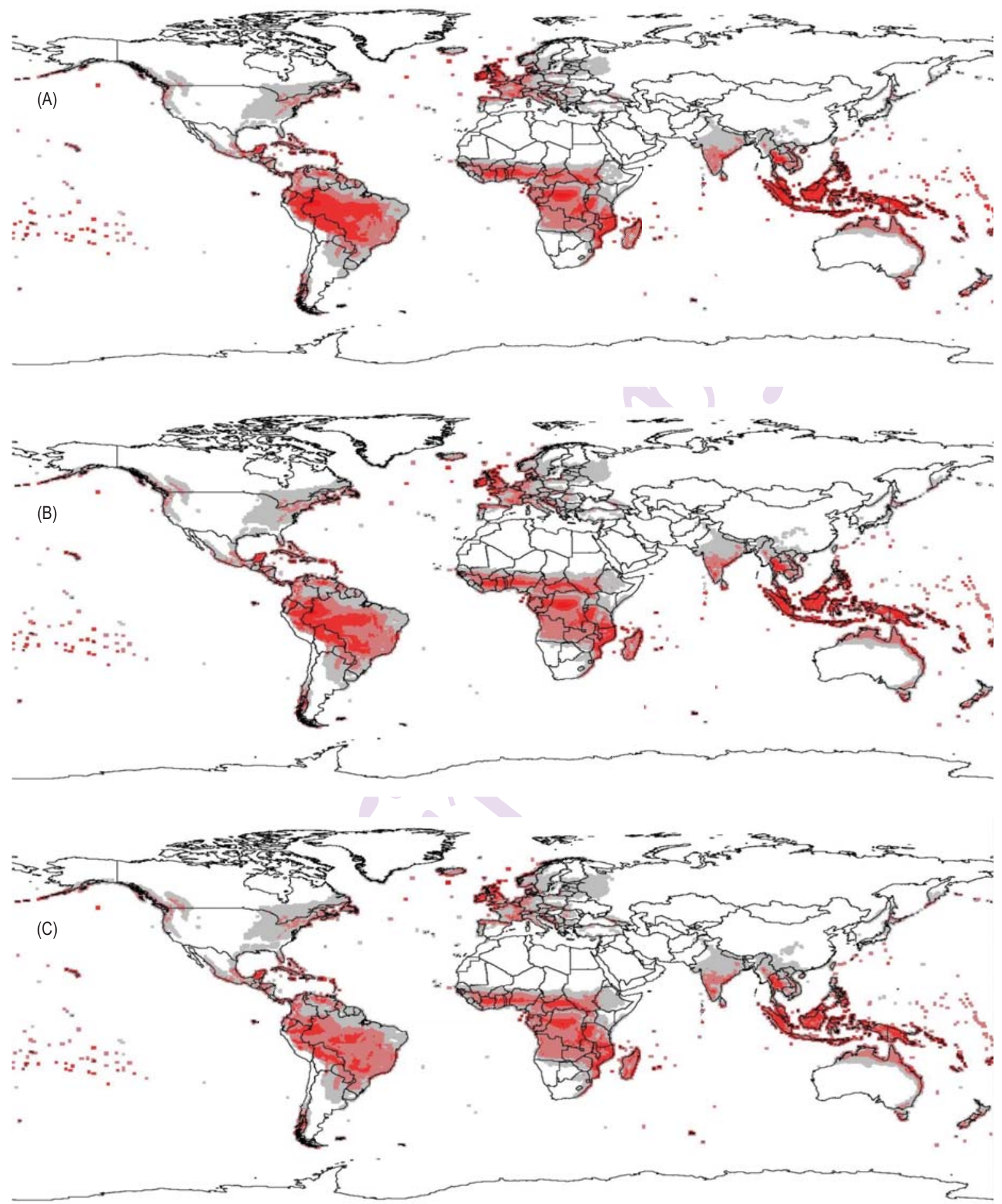

CMI values: $\square 0-0.6$ (0-60 \% matching); $\square 0.6-0.7$ (60-70\% matching); $\square 0.7-0.8$ (70-80\% matching); $\square$ 0.8-0.9 (80-90\% matching); $\square 0.9-1.0$ (90$100 \%$ matching)

Fig. 4 : Climatic similarity for $B$. papayae under climate change situations of (A) $1^{\circ} \mathrm{C},(\mathrm{B}) 2^{\circ} \mathrm{C}$ and $(\mathrm{C}) 3^{\circ} \mathrm{C}$ rise in temperature Journal of Environmental Biology, January 2017 


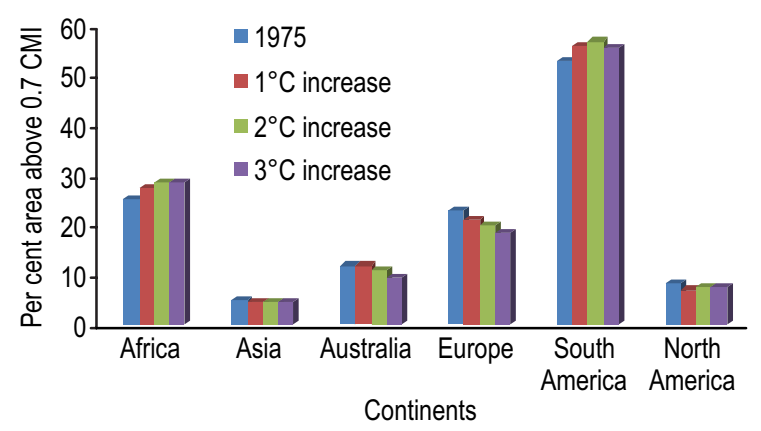

Fig. 5 : Per cent geographical area above $0.7 \mathrm{CMl}$ for base year, and for three future scenarios of $1^{\circ} \mathrm{C}, 2^{\circ} \mathrm{C}$ and $3^{\circ} \mathrm{C}$ rise in temperature for different continents

conditions with home locations, southern parts of Mexico, Guatemala, El Salvador, Belize, Honduras, Nicaragua, Panama, Bahamas, Turks and Caicos. In Europe, most of the north Western Europe was expected to have similar climatic conditions. Northern Portugal, Spain, most parts of France, Switzerland, Italy, England, Wales, Ireland, Scotland, Belgium, Netherland, Denmark, parts of Germany, Austria were expected to be climatically similar. Such closeness in climatic conditions would allow a successful establishment of the pest in this area, if it gains entry. Nevertheless, factors like host availability, presence of natural enemies etc. would enhance the accuracy of prediction. As biological control and quarantine measures are critical to limit the spread of invasive species, 'match climate function' used in the present study can play a significant role in understanding the distribution of invasive species. Similar observations with different pests were reported by Poutsma et al. (2008) and Sridhar etal. (2014b).

Strict quarantine measures and constant vigil in major hosts like like mango, papaya, banana, guava etc. needs to be done to monitor the incidence of $B$. papayae. Parts of Andaman and Nicobar Islands are proximal to the South EastAsia with high incidence of $B$. papayae. Hence, strict quarantine measures to check accidental entry of the pest needs to be undertaken in the entry ports and nearby islands of Andaman islands and this suitable zone needs to be closely monitored considering the frequent transport of commodities mainly exotic fruits like rambhutan, java apple, pomelo etc and movement of people between the Andaman and Nicobar islands and Indian main land. Although, the climatic suitability indicates possible pest invasion and establishment, role of availability of host flora, other biotic and abiotic factors in the spread and establishment of the pest needs further investigations.

The present findings emphasises the need for close monitoring in the regions predicted to have congenial climatic conditions for $B$. papayae establishment and suggests strict

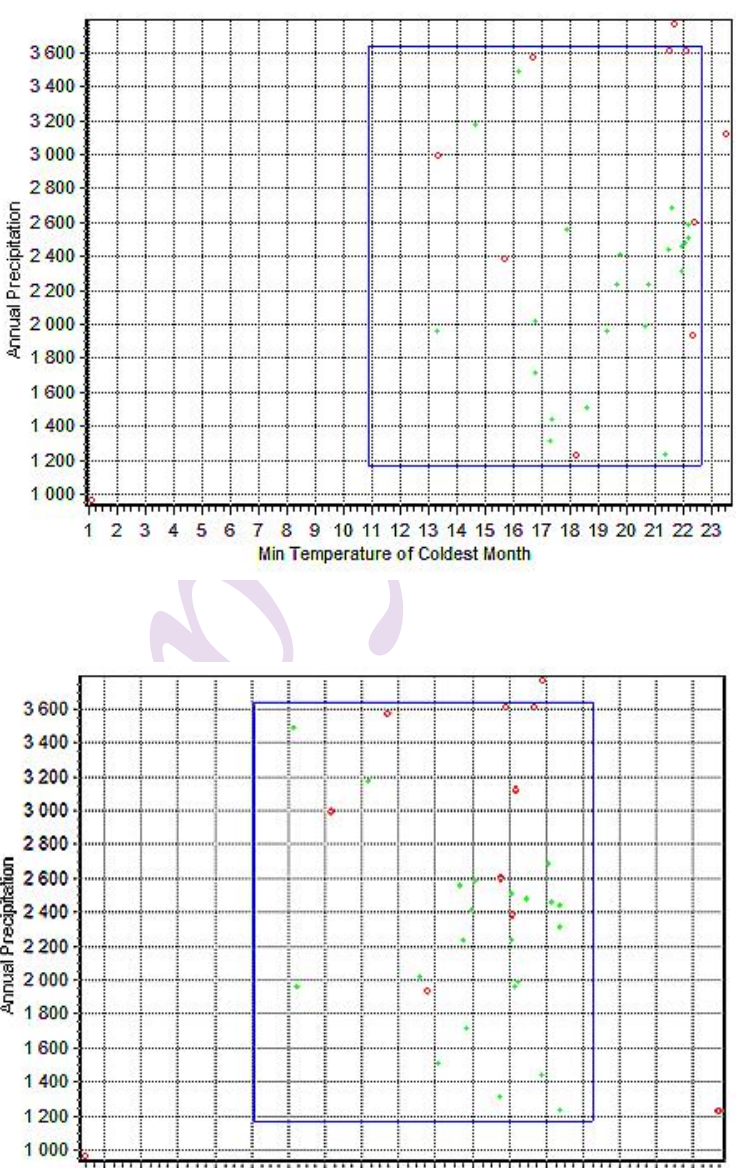

$\begin{array}{lllllllllllllllll}20 & 21 & 22 & 23 & 24 & 25 & 26 & 27 & 28 & 29 & 30 & 31 & 32 & 33 & 34 & 35 & 36\end{array}$ lax Temperature of Warmest Month

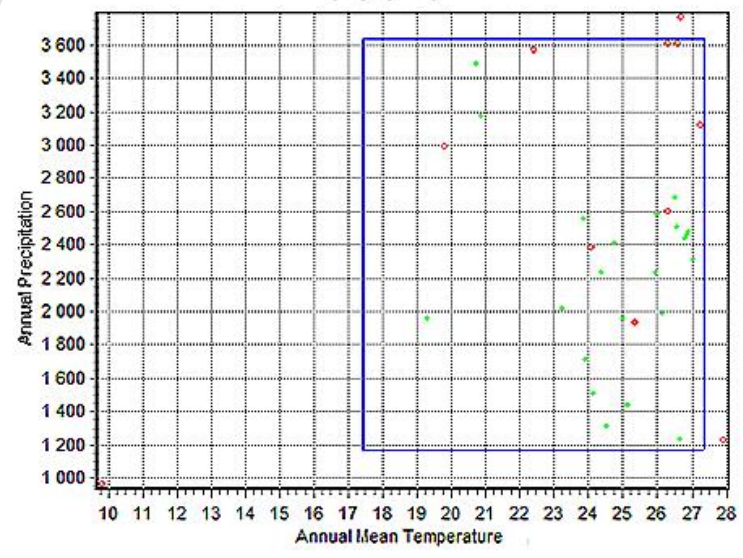

Fig. 6 : Climatic envelope for $B$. papayae obtained from DIVA GIS (a) Minimum temperature of the coldest month $\left(11-23^{\circ} \mathrm{C}\right)$, (b) maximum temperature at the warmest month $\left(24-33^{\circ} \mathrm{C}\right)$ and (c) Annual mean temperature with annual precipitation $\left(17-28^{\circ} \mathrm{C}\right.$ and $\left.1200-3600 \mathrm{~mm}\right)$ 
quarantine measures against the entry of the pest from existing to new regions in the world, particularly to India.

\section{Acknowledgments}

This study is a part of the ICAR sponsored project 'National Innovations in Climate Resilient Agriculture (NICRA)'. We thank the Director, ICAR-Indian Institute of Horticultural Research, Bengaluru for encouragement and providing us with the facilities.

\section{References}

Allwood, A.J., A. Chinajaryawong, R.A.I. Drew, E.L. Hamacek, D.L. Hancock, C. Hengsawad, J.C. Jipanin, M. Jirasurat, C. Kong Krong, S. Kritsaneepaiboon, C.T.S. Leong and S. Vijaysegaran: Host plant records for fruit flies (Diptera: Tephritidae) in South East Asia. Raffles Bull. Zool. Suppl., 7, 92 (1999).

Allwood, A.J. and L. Leblanc: Losses caused by fruit flies (Diptera: Tephritidae) in seven Pacific island countries. Pp. 208-211 In: Management of fruit flies in the Pacific (Eds.: A.J. Allwood and R.A.I. Drew). ACIAR Proceedings, Vol. 76. pp. 208-211 (1997).

Babasaheb, B.F.: Modeling the impact of climate change on potential geographic distribution of polyphagous mealybug Phenacoccus solenopsis in India. In proceeding of IV ${ }^{\text {th }}$ National Symposium on Plant Protection in Horticultural Ecosystems: Emerging Challenges and Sustainable Pest Management, pp.37-38 (2012) .

Baker, J. and M. Bomford: Opening the climate modeling envelope. Plant Prot. Q., 24, 88-91(2009).

Byrne, M.J., S. Currin and M.P. Hill: The influence of climate on the establishment and success of the biocontrol agent Gratiana spadicea, released on Solanum sisymbriifolium in South Africa. Biological Control, 24, 128-134 (2002).

CABI: Invasive Species Compendium. Wallingford, UK: CAB International. Available: www.cabi.org/isc (2015).

Cantrell, B., B. Chadwick and A. Cahill (Eds): Fruit fly fighters: Eradication of the papaya fruit fly. Commonwealth Scientific and Industrial Research Organisation Publishing, Collingwood, Australia. p. 200 (2002).

Clarke, A.R., K.F. Armstrong, A.E. Carmichael, J.R. Milne, G.K. Roderick and D.K. Yeates: Invasive phytophagous pests arising through a recent tropical evolutionary radiation: The Bactrocera dorsalis complex of fruitflies. Annu. Rev. Entomol., 50, 293-319 (2005).

Daniel, P.B.: Range-expanding pests and pathogens in warming world. Ann. Rev. Phytopathol., 53, 335-356 (2015).

Danjuma, S., S. Boonrotpong, N. Thaochan, S. Permkam and C. Satasook: Seasonality of the Asian fruit fly Bactrocera papayae Drew and Hancock (Diptera: Tephritidae) on guava Psidium guajava in peninsular Thailand. J. Ento. Zoo. Studies, 2, 276-284 (2014).

Drew, R.A.I. and D.L. Hancock: The Bactrocera dorsalis complex of fruit flies (Diptera: Tephritidae: Dacinae) in Asia. Bull. Entomol. Res., 84,68(1994).

Fay, H.A., R.A.I. Drew and A.C. Lloyd: The eradication program for papaya fruit fly (Bactrocera papayae Drew and Hancock) in north Queensland. In: Management of fruit flies in the Pacific (Eds.: A.J. Allwood and R.A.I. Drew). Aust. Cen. Int. Agri. Res., 76, 259-261 (1997).

Ganeshaiah, K.N., B. Narayani, N. Nilima, K. Chandrashekara, M.
Swamy and R. Uma Shaanker: Predicting the potential geographical distribution of the sugarcane woolly aphid using GARP and DIVA-GIS. Curr. Sci., 85, 1526-1528 (2003).

Hancock, D.L., E. Hamacek, A.C. Lloyd and M.M. Elson-Harris: The distribution and host plants of fruit flies (Diptera: Tephritidae) in Australia. Queensland Department of Primary Industries. Information Series Q199067, p. 75 (2000).

Hoelmer, K.A and A.A. Kirk: Selecting arthropod biological control agents against arthropod pests: Can the science be improved to decrease the risk of releasing ineffective agents? Biological Control, 34, 255-64 (2005).

IPCC: Climate change-The physical science basis. Contribution of Working Group to the Fourth Assessment Report of the Intergovernmental Panel on Climate Change. (Cambridge University Press, Cambridge, United Kingdom and New York) (2007).

Jeschke, J.M. and D.L. Strayer: Usefulness of bioclimatic models for studying climate change and invasive species. Ann. N. Y. Acad. Sci., 1134, 1-24 (2008).

Kriticos, D.J.: Regional climate-matching to estimate current and future sources of biosecurity threats. Biological Invasions, 14, 1533-1544 (2012).

Kriticos, D.J., B.L. Webber, A. Leriche, N. Ota, I. Macadam, J. Bathols and J.K. Scott: CliMond: global high resolution historical and future scenario climate surfaces for bioclimatic modeling. Methods Ecol. Evol., 3, 53-64 (2012).

Kumar, S., J. Graham, A.M. West and P.H. Evangelista: Using districtlevel occurrences in MaxEnt for predicting the invasion potential of an exotic insect pest in India. Comput. Elect. Agricult., 103, 55-62 (2014).

Liebhold, A.M., T.T. Work, D.G. McCullough and J.F. Cavey: Airline baggage as a pathway for alien insect species invading the United States. Amn. Entomol., 52, 48-54 (2006).

Mohamed, N.S. Insect Damage Post-harvest Operations http://www.fao.org/fileadmin/user_upload/inpho/docs/Post_Harv est_Compendium_-_Pests-Insects.pdf(1999).

Poutsma, J., A.J.M. Loomans, B. Aukema and T. Hejjeraman: Predicting the potential geographical distribution of the harlequin ladybird, Harmonia axyridis, using the CLIMEX model. Biological Control, 53, 103-125 (2008).

Rajasri, R., K.V. Gururaja and T.V. Ramchandra: Predictive distribution modelling for rare Himalayan medicinal plant Berberis aristata DC. J. Environ. Biol., 32, 725-730 (2011).

Rameshprabhu, N. and P.S. Swamy: Prediction of environmental suitability for invasion of Mikania micrantha in India by species distribution modelling. J. Environ. Biol., 36, 565-570 (2015).

Robertson, M.P., D.J. Kriticos and C. Zachariades: Climate matching techniques to narrow the search for biological control agents. Biological Control, 46, 442-452 (2008).

Robinet, C., H. Kehlenbeck, D.J. Kriticos, R.H.A. Baker, A. Battisti, S. Brunel, M. Dupin, D. Eyre, M. Faccoli, Z. llieva, M, Kenis, J. Knight, P. Reynaud, A. Yart and W. A. van der Werf: Suite of models to support the quantitative assessment of spread in pest risk analysis. PLoS ONE, 7, e43366 (2012).

Sar, S., S. Balagawi, A. Mararuai and D. Putulan: Fruit fly research and development in PNG. Food security for Papua New Guinea. Proceedings of the Papua New Guinea Food and Nutrition 2000 Conference, PNG University of Technology, Lae, Papua New Guinea, pp. 571-576 (2001). 
Senaratne, K.A.D.W., W.A. Palmer and R.W. Sutherst: Use of CLIMEX modeling to identify prospective areas for exploration to find new biological control agents for prickly acacia. Aust. J. Entomol., 45, 298-302 (2006).

Sridhar, V., V. Verghese, L.S. Vinesh, M. Jayashankar and P.D. Kamala Jayanthi: CLIMEX simulated predictions of Oriental fruit fly, Bactrocera dorsalis (Hendel) (Diptera: Tephritidae) geographical distribution under climate change situations in India. Curr. Sci., 106, 1702-1710 (2014a).

Sridhar, V., L.S. Vinesh and M. Jayashankar: Mapping Potential distribution of Achatina fulica (Gastropoda: Achatinidae) in India using CIIMEX. Pest Manag. Hortic. Ecosy., 20, 14-21 (2014b).

Sutherst, R.W.: Prediction of species geographical ranges. J. Biogeogr., 30, 805-816 (2003).

Sutherst, R. W. and R.B. Floyd: Impacts of global change on pests, diseases and weeds in Australian temperate forests. In: Impacts of Global change on Australian Temperate forests (Eds.: S. M.
Howden and J.T. Gorman), Working Paper Series 99/08, CSIRO, Australia. pp. 94-98 (1999).

Sutherst, R.W. and G. F. Maywald: A climate-model of the red imported fire ant, Solenopsis invicta Buren (Hymenoptera: Formicidae): Implications for invasion of new regions, particularly Oceania. Environ. Entomol. 34, 317-335 (2005).

Sutherst, R.W., G. F. Maywald and B.L. Russell: Estimating vulnerability under global change: modular modelling of pests. Agric. Ecosyst. Environ., 82, 303-319 (2000).

Tonnang, H.E.Z., S.F. Mohamed, F. Khamis and S. Ekesi: Identification and risk assessment for worldwide invasion and spread of Tuta absoluta with a focus on sub-Saharan Africa: Implications for phytosanitary measures and management. PLOS ONE, 10, e0135283 (2015).

Wee, S.K. and K.H. Tan: Interspecific mating of two sibling species of the Bactrocera dorsalis complex in a field cage. In: Area-wide control of fruit flies and other insect pests (Ed.: K.H. Tan). Pulau Pinang, Malaysia, Universiti Sains Malaysia, pp. 667-674 (2000). 